\title{
Normal value of pulsatility index of umbilical artery in second and third trimester of pregnancy
}

\author{
Ferdousi MA, Sharif MM, Mohiuddin AS, Shegufta F \\ Department of Radiology and Imaging, Bangladesh Institute of Research and Rehabilitation in Diabetes, \\ Endocrine and Metabolic Disorders (BIRDEM), Dhaka. \\ Email: mofazzalsharif@yahoo.com
}

\begin{abstract}
This cross sectional study was carried out on 60 pregnant Bangladeshi women in the department of Radiology and Imaging, BIRDEM for measurement of Pulsatility Index (PI) of umbilical artery of their fetuses by duplex colour Doppler sonography during $2^{\text {nd }}$ and $3^{\text {rd }}$ trimester of pregnancies. Considering total 2nd and 3rd trimesters the mean PI value of umbilical artery was 1.24 (SD \pm 0.27 ). While considering the gestational in separate trimesters, study showed that the value of PI in $2^{\text {nd }}$ trimester was $1.33(\mathrm{SD} \pm 0.29)$ and in $3^{\text {rd }}$ trimester PI was $1.18(\mathrm{SD} \pm 0.25)$. Paired t test shows there was a highly significant $(\mathrm{t}=35.79, \mathrm{df}=59$, Level of significance $=0.001)$ difference between mean values of PI in different gestational ages. It was observed that there was gradual decrease of PI value with increase of gestational age $(r=-0.207)$ but this decrease of PI was not statistically significant $(\mathrm{p}=0.113)$. Regression analysis between dependent PI value and independent gestational age showed linear negative relationship but this was not statistically significant $(\mathrm{p}=0.11)$. This study revealed that the Pulsatility index of umbilical artery was decreased with increase of gestational age from $2^{\text {nd }}$ to $3^{\text {rd }}$ trimester.
\end{abstract}

\section{Introduction}

Duplex color Doppler sonography is one of the popular imaging modalities in the department of radiology and imaging as well as to the physian to assay the condition of blood vessel and flow pattern in various diseases. Doppler ultrasound has an important contribution to make to the surveillance of fetus compromised by Intra Uterine Growth Retardation (IUGR), foetal hemolytic anemia, twin -twin transfusion syndrome and non -immune hydrops ${ }^{1-4}$. For obstetric and fetal purpose uterine artery, arcuate placental vessel of maternal part and uterine artery, aorta, middle cerebral artery, carotid, renal, ductus venosus of foetal part are examined. Placenta helps in gaseous exchange through two uterine arteries and one umbilical vein from mother to fetus. The umbilical arteries take origin from foetal internal iliac arteries The umbilical artery courses posteriorly and cephalad to join the left branch of the portal vein. The oxygenated blood is then shunted through liver to the IVC by ductus venosus. Spectral wave of the umbilical artery and vein can usually be easily obtained by using Doppler ultrasound ${ }^{2}$. Doppler velocimetry studies of foetal and placental circulation can provide an important information regarding wellbeing providing an opportunity to improve foetal outcome. Several studies show Doppler ultrasound in first trimester does not have any impact on pregnancy outcome. But Doppler ultrasound in $2^{\text {nd }}$ and $3^{\text {rd }}$ trimester play vital role in determining foetal outcome as Doppler wave form shows increased resistant to flow in $2^{\text {nd }}$ and $3^{\text {rd }}$ trimesters which are associated with poor pregnancy outcome $^{\mathbf{3}}$. For this continuous wave Doppler, pulse Doppler, color flow, power Doppler are utilized to measure PSV, EDV, PI, RI, and S/D ratio. Among all those parameters PI is the most important predictor of normal pregnancy outcome $\mathrm{e}^{\mathbf{4 , 5}}$.

There were very few studies conducted in Bangladesh regarding foetal Doppler indices measurement but none of these studies had been carried out to measure the PI value of umbilical artery as PI value was an important predictor of normal pregnancy outcome. ${ }^{4,5}$ The reference value for normal PI of umbilical artery which is currently used in Bangladesh was calculated in abroad enrolling normal healthy pregnant women who were socio-demographically different from the Bangladeshi women. So to establish a normal PI 
value of umbilical artery for Bangladeshi pregnant women and to see the change of PI value with advance of pregnancy from second to third trimester this present study was conducted in the department of Radiology and Imaging, BIRDEM, Bangladesh.

\section{Materials \& Methods}

This cross sectional study conducted in department of Radiology and Imaging in Bangladesh Institute of Research and Rehabilitation in Diabetes, Endocrine and Metabolic Disorders (BIRDEM) during the period of July 2009 to June 2010 among 60 Bangladeshi healthy pregnant women with the aim to measure the pulsatility index in umbilical artery of $2^{\text {nd }}$ and $3^{\text {rd }}$ trimester pregnancies and to find out relationship between PI value and gestational age. Study subjects were selected who had Singleton pregnancies without any foetal anomaly, had no history of Diabetes, Hypertension or any acquired illness. All the subjects underwent duplex Colour Doppler scanning of their fetus's umbilical artery after appropriate consent. Peak Systolic Velocities (PSV) and End-Diastolic Velocities (EDV) of the above artery were recorded for analysis. Then Pulsatility Index was calculated. Also Resistance Index (RI), Peak Systolic Velocities (PSV), End-Diastolic Velocities (EDV) were recorded.

\section{Results}

Maximum value for PI was 1.84 and the minimum value is 0.82 considering total trimester. The PI value (expressed as mean $\pm \mathrm{SD}$ ) in $2^{\text {nd }}$ trimester was $1.33( \pm 0.29)$ which decreased to $1.18 \pm 0.25$ in $3^{\text {rd }}$ trimester. Like PI value, RI value was also reduced from $0.75( \pm 0.06)$ to $0.69( \pm 0.7)$ while pregnancy was running from $2^{\text {nd }}$ to $3^{\text {rd }}$ trimester. Both PSV $(31.03 \pm 13.01$ to $33.42 \pm 15.21)$ and EDV $(8.98 \pm 7.36$ to $9.86 \pm 5.08)$ were increased from $2^{\text {nd }}$ to $3^{\text {rd }}$ trimester. Paired t test shows there was a highly significant $(t=35.79, d f=59$, Level of significance $=$ 0.001 ) difference between mean values of PI in different gestational ages. Pearson's correlation test shows there was a negative relationship between PI value $(r=-0.207)$ but this relationship was not statistically significant $(\mathrm{p}=0.113)$. Regression analysis between dependent PI value and independent gestational age showed linear negative relationship existed between value of PI and gestational age but this was not statistically significant $(\mathrm{p}=0.11)$.
Table I: Different Doppler variables in $2^{\text {nd }}$ and $3^{\text {rd }}$ trimesters.

\begin{tabular}{cccccccccccc}
\hline Measure & \multicolumn{2}{c}{$\mathrm{PI}$} & \multicolumn{2}{c}{ PSV } & \multicolumn{2}{c}{ EDV } & \multicolumn{2}{c}{$\mathrm{RI}$} \\
& $2^{\text {nd }}$ & $3^{\text {rd }}$ & $2^{\text {nd }}$ & $3^{\text {rd }}$ & $2^{\text {nd }}$ & $3^{\text {rd }}$ & $2^{\text {nd }}$ & $3^{\text {rd }}$ \\
\hline Mean & 1.33 & 1.18 & 31.03 & 33.42 & 8.98 & 9.86 & 0.75 & 0.69 \\
SD & 0.29 & 0.25 & 13.01 & 15.21 & 7.36 & 5.08 & 0.06 & 0.07 \\
Range & 0.97 & 0.88 & 45.83 & 61.27 & 28.43 & 24.95 & 0.21 & 0.37 \\
Minimum & 0.87 & 0.82 & 21.02 & 15.85 & 2.78 & 5.05 & 0.66 & 0.50 \\
Maximum & 1.84 & 1.70 & 66.85 & 77.12 & 31.21 & 30.00 & 0.87 & 0.87
\end{tabular}

Fig. 1: Regression analysis between PI value and gestational age

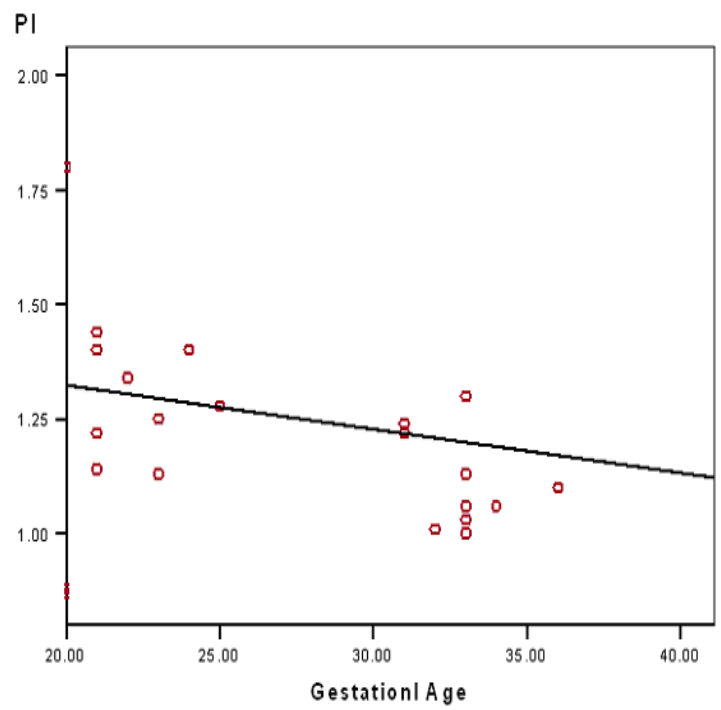

\section{Discussion}

Considering total 2 nd and 3rd trimesters the mean PI value of umbilical artery was 1.24 where standard deviation was \pm 0.27 . This result was very similar with the study conducted by Owen et al and Akiyama et al where mean PI value was 1.11 and 1.09 respectively ${ }^{\mathbf{4 , 5}}$. While considering the PI value range in third trimester in this study it was 0.88 $(0.82-1.70)$. It was observed that the range of PI in umbilical artery in $3^{\text {rd }}$ trimester was $1.0(0.6-1.6)$ in the study conducted by Owen et $a l^{4}$. This present study showed that the value of PI in $2^{\text {nd }}$ trimester $(1.33 \pm 0.29)$ decreased in $3^{\text {rd }}$ trimester $(1.18 \pm 0.25)$. This finding was also consistent with the study carried out by Bewley et al, Schulman et al, Owen et $a l$ and Akiyama et $a l^{4-7}$. Like PI value RI value was also reduced from $0.75 \pm 0.06$ to $0.69 \pm 0.7$ while pregnancy was running from $2^{\text {nd }}$ to $3^{\text {rd }}$ trimester. The gradual decrease of PI value with increase of gestational age was due to a negative relationship 
between PI value and gestational age but this relationship was not statistically significant. There was also similarity with the study conducted by Owen et al where it was observed that regression analysis between dependent PI value and independent gestational age had linear negative relationship ${ }^{4}$. Mean PSV and EDV of umbilical artery of study subjects were $32.52 \pm 14.04 \mathrm{~cm} / \mathrm{sec}$ and $09.47 \pm 05.54 \mathrm{~cm} / \mathrm{sec}$ respectively. Both PSV $(31.03 \pm 13.01$ to $33.42 \pm 15.21)$ and EDV $(8.98 \pm 7.36$ to $9.86 \pm 5.08$ ) were increased from 2 nd to $3 \mathrm{rd}$ trimester. This revealed that with advance of gestational age foetal vascular resistance increased.

Conclusion: Considering total trimesters the mean PI was 1.24. While considering the gestational age in separate trimesters, this study revealed that the value of PI in $2^{\text {nd }}$ trimester was $1.33 \pm 0.29$ and in $3^{\text {rd }}$ trimester PI was $1.18 \pm 0.25$. RI value was $0.75 \pm 0.06$ in $2^{\text {nd }}$ trimester and $0.69 \pm 0.7$ in $3^{\text {rd }}$ trimester. Both PSV (31.03 \pm 13.01 to $33.42 \pm 15.21)$ and EDV (8.98 \pm 7.36 to $9.86 \pm 5.08)$ were increased from $2^{\text {nd }}$ to $3^{\text {rd }}$ trimester. It could be concluded that Pulsatility index of umbilical artery was decreased with increase of gestational age from $2^{\text {nd }}$ to $3^{\text {rd }}$ trimester. Like Pulsatility index Resistance Index was also decreased with increase of gestational age. But Peak Systolic Velocities and End-Diastolic
Velocities were increased with advance of gestational age.

\section{References}

1. Rumack CM, Wilson SR, Charboneau JW (2005): Diagnostic ultrasound $3^{\text {rd }}$ Ed. Misouri.

2. Paul LA, Paul AD, Myron AP, Mc Dicken WN (2006): Clinical Doppler Ultrasound $2^{\text {nd }}$ Ed. Elsevier Limited.

3. Bromley B, Frigoletto FD, Harlow BL, Pauker S, Benacerraf BR (1998): Clinical sonography: A practical guide $3^{\text {rd }}$ Ed. Lippincott-Raven Publishers.

4. Owen P, Murphy J, Farrell T (2003): Is there a relationship between estimated fetal weight and umbilical artery Doppler impedance indices? Ultrasound in Obstetrics and Gynecology; 22:157-159.

5. Akiyama1 M, Kuno A, Tanaka Y, Tanaka H, Hayashi K, Yanagihara T, Hata T (1999): Comparison of alterations in fetal regional arterial vascular resistance in appropriate-for-gestational-age singleton, twin and triplet pregnancies. Human Reproduction; 14: 2635 2643.

6. Bewly S, Campbell S. Cooper D (1989): Uteroplacental Doppler flow velocity waveforms in the second-trimester- A complex circulation. British Journal of Obstetrics and Gynaecnlogy; 96: 1040-1046.

7. Schutman H, Winter I, Farmakides G, Coury A, Schneider E, Penny B (1989): Doppler examinations of the umbilical and uterine arteries during - pregnancy. Clinical Obstetrics and Gynaecology; 32: 738-745. 